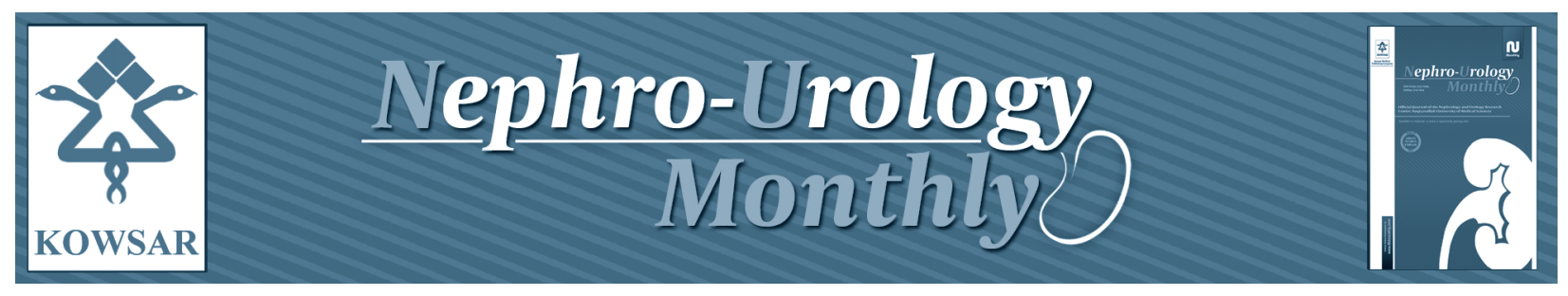

\title{
Role of Renal Re-transplantation in ESRD Patients
}

\author{
Alireza Ghadian ${ }^{1,}$, , Mohammad Hossein Nourbala ${ }^{1}$ \\ ${ }^{1}$ Nephrology and Urology Research Center, Baqiyatallah University of Medical Sciences, Tehran, IR Iran \\ *Corresponding author: Alireza Ghadian, Nephrology and Urology Research Center, Baqiyatallah University of Medical Sciences, Tehran, IR Iran. Tel: +98- \\ 2181262073, Fax:+98-2181262073, E-mail:p_ghadian@yahoo.com.
}

Keywords: Transplant; Kidney Failure, Chronic

Although there is no data to prove the role of renal retransplantation, but it is presumed to be a favorable option for many patients after graft loss. Re-transplantation often provides a better survival and good health in comparison with dialysis, that is more obvious for younger recipients and whom receives transplantation either preemptively or shortly after the need for renal replacement therapy has arisen (1). Although some authors believe that for older patients, dialysis is a better option (2). Indeed the type of dialysis doesn't have any influence on the outcome of transplantation (3).

The etiology of their initial graft loss varies in candidates of kidney re-transplantation depends on the time of graft loss. If graft loss occurred within the first year after transplantation, the most common etiologies are acute rejection and graft thrombosis and if this occurred after 1 year of transplant, chronic rejection accounts for nearly two thirds of the graft loss (4).

In recent decades, kidney re-graft survival has been improved and this improvement is more obvious for grafts from cadaveric source (graft half-life has been increased from 2.0 years in 1988 to 7.5 years in 1995) in comparison with living donors (5) and is suggested that this improvement is the result of improved HLA testing and improvements in immunosuppressive agents (1). 5-year survival after re-transplantation in deceased donors and living donors is as the same as primary transplantation in patients with hypertension, diabetes and renovascular diseases but is less favorable in recipients with polycystic kidney disease (PKD) or glomerular disease (6).

Many variables have an effect on re-transplantation outcome, such as recipient comorbidities, outcome of primary transplant, risk of recurrent disease and the wait time on dialysis before transplantation (1). CKD will occur in the majority of transplanted kidneys that is due to many etiologies include chronic rejection, recurrent disease, calcineurin toxicity and underlying diseases such as diabetes, hypertension and atherosclerosis (1).

Early graft loss after previous transplantation is a predictor of the occurrence of the same process after retransplantation and so the recipient and potential donors should be evaluated very precisely. This early graft rejection can be due to many factors such as acute rejection, FSGS, IgA nephropathy, MPGN, thrombotic microan-

-Article type: Editorial; Received: 02 Mar 2013, Accepted:11 Mar 2013; DOI: 10.5812/numonthly.11155

-Implication for health policy/practice/research/medical education:

It is about the advantages of renal re-transplantation for patients with a history of previous grafting.

Please cite this paper as:

Ghadian A, Nourbala MH. Role of Renal Re-transplantation in ESRD Patients. Nephro Urol Mon.2013;5(2): 721-2. DOI: 10.5812/numonthly.11155

Copyright (C) 2013, Nephrology and Urology Research Center; Published by Kowsar Corp.

This is an Open Access article distributed under the terms of the Creative Commons Attribution License (http://creativecommons.org/licenses/by/3.0), which permits unrestricted use, distribution, and reproduction in any medium, provided the original work is properly cited. 
giopathy or vascular events (7). Polyoma virus (BK virus) is a known cause of graft loss with increasing incidence and so should be assessed before re-transplantation (8).

The proper time for evaluating recipient and donors for re-transplantation is when the GFR falls to less than 20 $\mathrm{mL} / \mathrm{min}(9,10)$. Routine evaluations before re-transplantation are screening for colon, lung, breast, heart, prostate and systemic diseases and malignancies as the same as first transplantation.

Presence of antibodies, that may be created previous blood transfusion, pregnancies or previous transplantation, is a great concern before transplantation (11). Antibodies that are due to graft rejection are absorbed by the graft and after performing nephrectomy for graft loss, they will appear in the plasma with higher concentration and after that will gradually decrease and even may disappear from plasma (12) and evaluation of recipient for these antibodies should be performed with high sensitive assays that will result in avoidance of re-grafting from suspicious donors or using desensitization methods (11). If the patient is highly sensitized to HLA of all potential living donors, the possibility of finding a proper deceased donor is very low, so desensitization is necessary, using high dose gamaglobulin (IVIG) (13) or low dose IVIG with plasma-pheresis (14) and immunosuppression induction with polyclonal antibodies plus low dose IVIG (15). These protocols can be used also for ABO incompatibility (16).

In re-transplantation immunosuppressive agents are used to prevent acute graft loss but risk of infection and malignancies increase. It should be kept in mind that retransplant patients are at higher risk for acute rejection in comparison with first graft patients (16).

Reasons for previous transplant nephrectomy include: symptoms of graft loss, infections, proteinuria, severe hematuria, the need for more space in the pelvic fossa but in about $80 \%$ of these patients, there is no need for previous graft nephrectomy before re-transplantation (16).

In theory, there isn't any limitation for the number of renal re-transplantation in a patient with ESRD but vascular anatomy can restrict it, so evaluation of the vascular anatomy of recipients before re-transplantation is very important $(1,17)$.

\section{Authors' Contribution}

None declared.

\section{Financial Disclosure}

There is no conflict of interest.

\section{References}

1. Koch MJ. Considerations in retransplantation of the failed renal allograft recipient. Adv Chronic Kidney Dis.2006;13(1):18-28.

2. Andrew Smyth . End-Stage Renal Disease and Renal Replacement Therapy in older Patients. Nephro-Urol Mon.2012;4(2):425-30.

3. Mohammadreza Ardalan Jalal Etemadi, Kamyar Ghabili, Mortaza Ghojazadeh, Ali Ghafari, Hamid Tayebi Khosroshahi. Effect of Dialysis Modality on Transplantation Outcome in Living-Donor Renal Transplantation. Nephro-Urol Mon.2011;3(4):285-90.

4. Magee JC, Barr ML, Basadonna GP, Johnson MR, Mahadevan S, McBride MA, et al. Repeat organ transplantation in the United States, 1996-2005. Am J Transplant.2007;7(5 Pt 2):1424-33.

5. Meier-Kriesche HU, Schold JD, Kaplan B. Long-term renal allograft survival: have we made significant progress or is it time to rethink our analytic and therapeutic strategies? Am J Transplant.2004;4(8):1289-95.

6. 2004 Annual Report of the U.S. Organ Procurement and Transplantation Network and the Scientific Registry of Transplant Recipients: Transplant Data 1994-2003. Department of Health and Human Services, Health Resources and Services Administration, Healthcare Systems Bureau, Division of Transplantation, Rockville, MD; United Network for Organ Sharing, Richmond, VA; University Renal Research and Education Association, Ann Arbor, MI. Available from: http://optn.transplant.hrsa.gov/data/citing.asp.

7. Stephanian E, Matas AJ, Mauer SM, Chavers B, Nevins T, Kashtan $\mathrm{C}$, et al. Recurrence of disease in patients retransplanted for focal segmental glomerulosclerosis. Transplantation.1992;53(4):755-7.

8. Ramos E, Vincenti F, Lu WX, Shapiro R, Trofe J, Stratta RJ, et al Retransplantation in patients with graft loss caused by polyoma virus nephropathy. Transplantation.2004;77(1):131-3.

9. Meier-Kriesche HU, Port FK, Ojo AO, Rudich SM, Hanson JA, Cibrik DM, et al. Effect of waiting time on renal transplant outcome. Kidney Int.2000;58(3):1311-7.

10. Meier-Kriesche HU, Kaplan B. Waiting time on dialysis as the strongest modifiable risk factor for renal transplant outcomes: a paired donor kidney analysis. Transplantation.2002;74(10):1377-81

11. Farney AC, Matas AJ, Noreen HJ, Reinsmoen N, Segall M, Schmidt WJ, et al. Does re-exposure to mismatched HLA antigens decrease renal re-transplant allograft survival? Clin Transplant.1996;10(2):147-56.

12. Arnold ML, Pei R, Spriewald B, Wassmuth R. Anti-HLA class II antibodies in kidney retransplant patients. Tissue Antigens.2005;65(4):370-8.

13. Jordan SC, Vo A, Bunnapradist S, Toyoda M, Peng A, Puliyanda D, et al. Intravenous immune globulin treatment inhibits crossmatch positivity and allows for successful transplantation of incompatible organs in living-donor and cadaver recipients. Transplantation.2003;76(4):631-6.

14. Montgomery RA, Zachary AA, Racusen LC, Leffell MS, King KE, Burdick J, et al. Plasmapheresis and intravenous immune globulin provides effective rescue therapy for refractory humoral rejection and allows kidneys to be successfully transplanted into cross-match-positive recipients. Transplantation.2000;70(6):887-95.

15. Akalin E, Ames S, Sehgal V, Fotino M, Daly L, Murphy B, et al. Intravenous immunoglobulin and thymoglobulin facilitate kidney transplantation in complement-dependent cytotoxicity B-cell and flow cytometry T- or B-cell crossmatch-positive patients. Transplantation.2003;76(10):1444-7.

16. Gloor JM, Lager DJ, Moore SB, Pineda AA, Fidler ME, Larson TS, et al. ABO-incompatible kidney transplantation using both $\mathrm{A} 2$ and non-A2 living donors. Transplantation.2003;75(7):971-7.

17. Pour-Reza-Gholi F, Nafar M, Saeedinia A, Farrokhi F, Firouzan A Simforoosh N, et al. Kidney retransplantation in comparison with first kidney transplantation. Transplant Proc.2005;37(7):2962-4. 